\title{
Expression of SAMDC Gene for Enhancing the Shelf Life for Improvement of Fruit Quality Using Biotechnological Approaches into Litchi (Litchi chinensis Sonn.) Cultivars
}

\author{
Dilip Kumar Das*, Manoj Prabhakar, Dipti Kumari, Nutan Kumari \\ Post Graduate Department of Biotechnology, T.M. Bhagalpur University, Bihar, India \\ Email: "dilipdas1@live.com
}

Received 11 November 2015; accepted 27 June 2016; published 30 June 2016

Copyright (C 2016 by authors and Scientific Research Publishing Inc.

This work is licensed under the Creative Commons Attribution International License (CC BY).

http://creativecommons.org/licenses/by/4.0/

(c) (i) Open Access

\begin{abstract}
Polyamines play an important role in plant response to abiotic stress. S-adenosyl-1-methionine decarboxylase (SAMDC) is one of the key regulatory enzymes in the biosynthesis of polyamines. In order to better understand the effect of regulation of polyamine biosynthesis on the shelf life improvement of litchi fruit, $S A M D C$ cDNA isolated from Datura stramonium cloned in pBI121 was introduced into litchi genome by means of Agrobacterium tumefaciens through zygote disc transformation. Transgene and its expression are confirmed by Southern and Northern blot analyses, respectively. Transgenic plants expressing Datura SAMDC produced 1.7- to 2.4-fold higher levels of spermidine and spermine than wild-type plants under normal environmental condition, which indicated that the transgenic litchi presented an enhanced polyamines synthesis compared to wildtype plants. Our results demonstrated clearly that increasing polyamine biosynthesis in plants may be a means of creating improved fruit shelf life germplasm.
\end{abstract}

\section{Keywords}

Shelf Life, Litchi chinensis Sonn., Datura stramonium, S-Adenosylmethionine Decarboxylase, Polyamines, Transformation

\section{Introduction}

Litchi (Litchi chinensis Sonn.) is native to Southern China, which is adapted to the warm subtropics, cropping

${ }^{*}$ Corresponding author.

How to cite this paper: Das, D.K., Prabhakar, M., Kumari, D. and Kumari, N. (2016) Expression of SAMDC Gene for Enhancing the Shelf Life for Improvement of Fruit Quality Using Biotechnological Approaches into Litchi (Litchi chinensis Sonn.) Cultivars. Advances in Bioscience and Biotechnology, 7, 300-310. http://dx.doi.org/10.4236/abb.2016.76028 
best in regions with brief cool dry frost-free winters and long hot summers with high rainfall and humidity [1]. It has a short shelf-life under normal ambient conditions due to skin color loss (browning) and deterioration during storage and transportation [2]. The fruit easily loses its commercial value after harvest due to pericarp browning, quality deterioration and decay [3]. Browning of litchi pericarp is still considered to be a major problem affecting its market value. Browning of litchi pericarp was thought to be due to degradation of anthocyanidin by polyphenol oxidase (PPO) and peroxidase (POD) [4] [5] and was primarily the result of PPO activity degrading the anthocyanins and producing brown-coloured by-products [6].

While polyamines (PAs) inhibit senescence of leaves [7], cell cultures of many plant species [8] and fruit ripening [9] ethylene promotes these processes. The most commonly held view is that PAs and ethylene regulate each other's synthesis, either directly or through metabolic competition for S-adenosylmethionine (SAM), a common precursor for their biosynthesis. PAs inhibit ethylene biosynthesis, perhaps by blocking the conversion of SAM to 1-aminocyclopropane-1-carboxylic acid (ACC) and of ACC to ethylene [10]-[13]. Ethylene, on the other hand, is an effective inhibitor of arginine decarboxylase (ADC) and S-adenosylmethionine decarboxylase (SAMDC), key enzymes in PA biosynthetic pathway [14] [15]. Thus, PAs may affect senescence and fruit ripening by modulating PA and ethylene biosynthesis. Their biosynthetic enzymes are associated with rapid cell division in many plant systems, e.g., carrot embryogenesis [16] [17], tomato ovaries [18], tobacco ovaries [19], and fruit development [9].

PA biosynthesis regulated by S-adenosylmethionine decarboxylase [20] gene in rice, tobacco, Arabidopsis and sweet potato plants. SAMDC is one of the key regulatory enzymes in the biosynthesis of polyamines. Since ripening process in litchi is non-climacteric i.e. not dependent on ethylene, by the insertion of SAMDC gene it will make SAMDC enzyme which catalyzes SAM to form decarboxylated SAM which provides the aminopropyl groups for subsequent spermidine (Spd) and spermine (Spm), so that ethylene production will decline and polyamines concentration will increase so that fruit ripening process will be delayed due to high levels of polyamines concentration [21]. It is believed that the synthesis of Spd and Spm is mainly regulated by the level of SAMDC. The SAMDC primary sequences in higher plants are similar. Therefore, the SAMDC gene isolated from Datura stramonium was selected and introduced into litchi plant to avoid the homologous depression in the present work. The response of transgenic plants to high polyphenols secrection was investigated in order to obtain some fundamental information on the role of PAs during fruit ripening. Indeed, over expression of Datura SAMDC gene (dSAMDC) in transgenic litchi plants led to increase in PA content that helps to increase the fruit shelf life. Our results would be providing the helpful tool for understanding the physiological function of polyamines which play an important role in fruit shelf life improvement in litchi plant.

\section{Materials and Methods}

\subsection{Plant Material and Plasmid}

The seeds of Litchi (Litchi chinensis Sonn.) cv. "Bedana” were obtained from Bihar Agricultural University, Sabour, Bhagalpur, Bihar, India. The Agrobacterium tumefaciens strain LBA4404 containing binary plasmid pBI121 with SAMDC gene from Datura stramonium under the control of cauliflower mosaic virus CaMV35S promoter and nopaline synthase terminator, and hygromycin phosphotransferase (hpt) as plant selection marker was used for litchi transformation [22] (Figure 1). An empty pBI121 vector not carrying SAMDC gene was also transferred into Agrobacterium tumefaciens strain LBA4404 as positive control.

\subsection{Litchi Transformation and Regeneration}

Litchi immature seed explants, collected from about 6 - 7 weeks, were used for transformation. The Agrobacterium culture grown to an O.D. (A600) of 0.1 - 0.2 was used for infection (10 min) on 2 days old precultured explants (zygotic embryos), grown on calli regeneration medium (CRM). Without antioxidants presoaked zygotic embryos were carefully removed and transferred onto induction medium (MS1), which consisted of MS salts and B5 vitamin with $2 \mathrm{mg} \cdot \mathrm{l}^{-1}$ 2, 4-D (2, 4-dichlorophenoxyacetic acid), $50 \mathrm{~g} \cdot \mathrm{l}^{-1}$ sucrose and $8 \mathrm{~g} \cdot \mathrm{l}^{-1}$ agar (pH 5.8). With antioxidants pre-soaked zygotic embryos were transferred onto induction medium (MS1) containing the tested concentrations of anti-browning agents (combination of ascorbic acid and citric acid) were $160 \mathrm{mg} \cdot \mathrm{l}^{-1}$. MS1 medium was sterilized by autoclaving at $120^{\circ} \mathrm{C}$ and $1.1 \mathrm{~kg} \cdot \mathrm{cm}^{-2}$ for $15 \mathrm{~min}$. The Cultures were maintained in darkness at $26^{\circ} \mathrm{C} \pm 2^{\circ} \mathrm{C}$. The embryogenic cultures were pale yellow and friable appeared after 6 - 8 weeks [23]. The embryos were sub cultured in every 2 weeks interval on fresh MS1 or MS2 (MS1 plus STS $29.4 \mu \mathrm{M}$ ) 


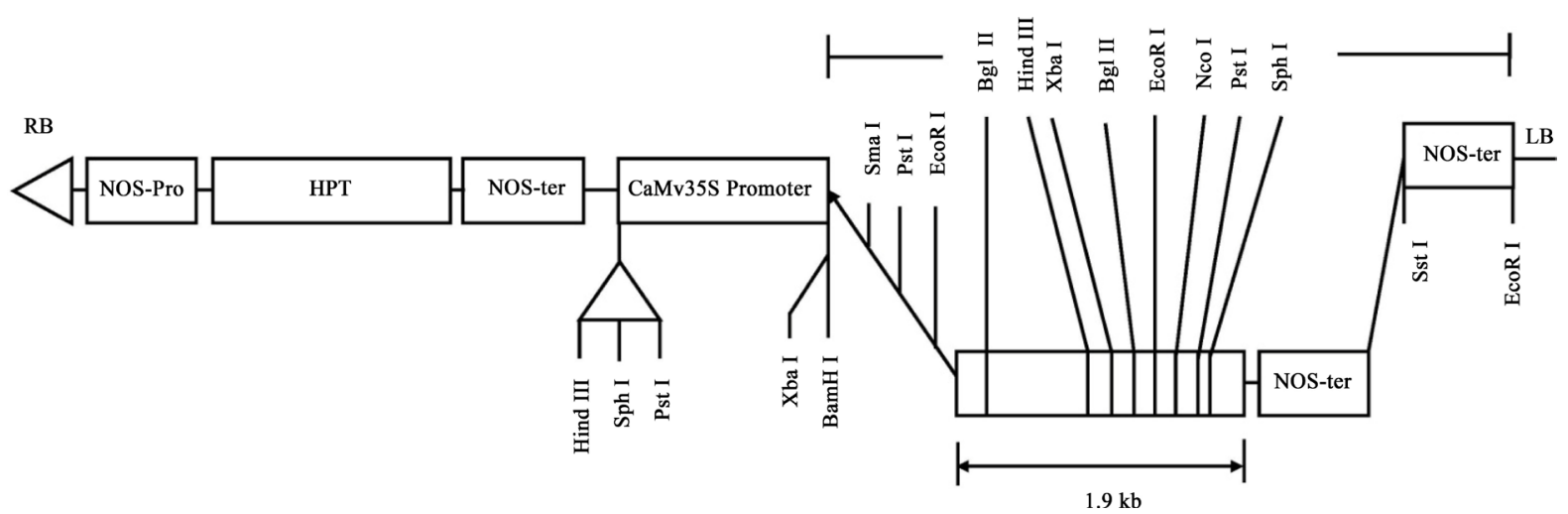

Figure 1. A complete map for pBI 121-35S—SAMDC transforming vector (Datura SAMDC cDNA in pBI 121).

with addition of antioxidants. The STS stock solution was prepared as follows: $0.1 \mathrm{M}$ sodium thiosulphate and 0.1 M silver nitrate were prepared separately in distilled water; 0.02 M STS (Sodium thosulphate) stock solution was prepared by slowly pouring $20 \mathrm{ml}$ of $0.1 \mathrm{M}$ silver nitrate to $80 \mathrm{ml}$ of $0.1 \mathrm{M}$ of sodium thiosulphate. The STS solution was filter sterilized and added to autoclaved MS1 to form the final concentration of 29.4 $\mu \mathrm{M}$ [24]. According to a number of workers [25], culturing on medium supplemented with 2, 4-D followed by growth of the callus onto medium devoid of 2,4-D, gives rise to somatic embryos and eventually to plantlets. For germination of naked white to yellowish, opaque, cotyledonary-stage somatic embryos were cultured on MS agar medium containing B5 macrosalts, MS microsalts, iron EDTA (Ethylene diamine tetra acetic acid), organics with 3\% sucrose and $0.7 \%$ agar supplemented with $2.9 \mu \mathrm{M} \mathrm{GA}_{3}$ (Gibberellic acid) with addition of higher concentrations (0.04, 0.2 and $0.4 \mu \mathrm{M}$ ) of ABA (Abscisic acid). Each experimental treatment was repeated five times.

\subsection{Polymerase Chain Reaction}

The putative transgenic plants were analyzed by PCR for the integration of the transgene. DNA was isolated from the leaf explants by CTAB (Cetyl trimethyl ammonium bromide) method. About 100 ng of DNA from untransformed plants as well as putative transgenic lines was taken and mixed with $100 \mathrm{mM}$ of primer pair, $7.5 \mu \mathrm{l}$ of PCR buffer, $100 \mathrm{mmol} \cdot \mathrm{l}^{-1} \mathrm{dNTP}$ mix and $0.5 \mathrm{U}$ of Taq DNA polymerase for $50 \mu \mathrm{l}$ reaction mixture (MBI, Fermentas). The PCR program included denaturation at $94{ }^{\circ} \mathrm{C}$ for $5 \mathrm{~min}$ followed by 30 cycles of denaturation at $94^{\circ} \mathrm{C}$ for $30 \mathrm{~s}$, annealing at $56^{\circ} \mathrm{C}$ for $45 \mathrm{~s}$ and synthesis at $72^{\circ} \mathrm{C}$ for $45 \mathrm{~s}$ and finally 1 cycle of 7 min at $72^{\circ} \mathrm{C}$. The primer pairs specific for the amplification of a 1.9-kb fragment of SAMDC gene 5'-GTATACCCGTGGGAG CTTCA-3'and 5'-TCTCCCTGTCCAAACCAGTC-3'.

\subsection{Southern Blot Hybridization}

Litchi genomic DNA (10 mg) was restricted with EcoRI to detect the copy number of the transgene. Southern blots were prepared by standard procedure [26] using Hybond-N Nylon membrane (Pharmacia). The hpt gene probes were prepared using ${ }^{32} \mathrm{P}$-labeled dCTP by nick translation as the manufactures guidelines (Gibco-BRL). Hybridization was carried out for $18-22 \mathrm{~h}$ at $65^{\circ} \mathrm{C}$. Signals were detected by exposure of storage phosphor screens, which were scanned in a Typhoon TM 9400 (GE Healthcare).

\subsection{RNA Extraction, RT-PCR and Northern Blot}

Total RNA was isolated using TRIzol ${ }^{\circledR}$ (Invitrogen) as a template and the cDNA was made using SMARTTM PCR cDNA Synthesis Kit according to the manufacture (Clontech). The $20 \mu \mathrm{l}$ of reaction mixture included $1 \times$ PCR reaction buffer, $400 \mathrm{mM}$ of dNTPs, $1.2 \mathrm{mmol} \cdot \mathrm{l}^{-1}$ of each primer, $2 \mathrm{U}$ Taq Polymerase and $1.2 \mu \mathrm{L} \mathrm{cDNA}$. The reaction mixture was heated to $95^{\circ} \mathrm{C}$ for $10 \mathrm{~min}$, followed by 30 cycles of $30 \mathrm{~s}$ denaturation at $94^{\circ} \mathrm{C}$, annealing at $53^{\circ} \mathrm{C}$ for $30 \mathrm{~s}$, extension at $72^{\circ} \mathrm{C}$ for $1 \mathrm{~min}$ and final extension for $10 \mathrm{~min}$. The PCR products were analyzed on $1 \%$ agarose gel. Twenty micrograms of total RNA were electrophoresed through a $1.2 \%$ (w/v) denaturing formaldehyde/agarose gel, blotted to a Nitran filter by the capillary blot method. Prehybridization and hybridization were done in $50 \%$ formamide buffer using an $\left[{ }^{32} \mathrm{P}\right]$-labeled SAMDC cDNA probe at $42^{\circ} \mathrm{C}$. Yeast 
specific SAMDC cDNA 1 fragment was labeled using Random Priming Labeling Kit (Promega, Shanghai, China) with $\alpha-\left[{ }^{32} \mathrm{P}\right]$ dCTP. Washing of the filter was carried out first with $2 \times$ SSC, $0.5 \%$ SDS for 7 min and then $1 \times \mathrm{SSC}, 0.5 \% \mathrm{SDS}$ at $55^{\circ} \mathrm{C}$ for $4 \mathrm{~min}$.

\subsection{Analysis of Polyamines}

PAs were estimated in seedlings of the wild-type and transgenic lines according to the protocol of [27]. Litchi leaves $(0.4 \mathrm{~g})$ from 5 seedlings were pooled and powdered with nitrogen, then extracted with 10 volumes of $4 \%$ perchloric acid (PCA) and centrifuged at 20,000 g for $30 \mathrm{~min}$ at $4^{\circ} \mathrm{C}$. Aliquots $(0.2 \mathrm{ml})$ of the supernatant containing free polyamines were dansylated, extracted in toluene and analysed by HPLC on a reverse phase C18 column using a programmed acetonitrile: water step gradient, respectively, with $1 \mathrm{ml} \cdot \mathrm{min}^{-1}$ flow rate. Eluted peaks were detected with a fluorescence spectrophotometer at excitation and emission wavelengths of 360 and $506 \mathrm{~nm}$ and their areas were recorded and integrated relative to those of standard PAs (Sigma, USA). Three extractions of polyamines were made from each sample and each extraction was quantified by HPLC in duplicate.

\section{Results}

\subsection{Transformation and in Vitro Regeneration of Plants}

Many concentrations and combinations of ascorbic acid (AA) and citric acid (CA) were used to define an efficient antioxidant to check browning as well as promote calli formation for litchi regeneration from explants. Calli formation was observed only in zygotic embryos cultured on MS1 medium added with antioxidant. Embryos failed to respond in the absence of antioxidant. Antioxidants lowered down the polyphenol oxidase (PPO) activity, at the time of incision of zygote. PPO activity was found maximum but it gradually reduced the PPO activity under the control of different antioxidant in different ratio with time interval (Table 1). The combination of AA and CA increased the percentage of somatic embryogenesis and the development of the somatic embryos. While, in MS1 medium, without antioxidant we found that percentage of somatic embryogenesis and the development of the somatic embryos from explants were very low. Combination of AA and CA initiated somatic embryos formation. Optimum values for calli induction from zygotic embryos were obtained in MS2 medium (MS1 plus STS $29.4 \mu \mathrm{M}$ ) with addition of equal conc. of AA and CA $\left(160 \mathrm{mgl}^{-1}\right)$. One hundred percent of explants cultured on this medium turned light pale color and we observed the proliferation of callus (Figure 2). Primary somatic embryos were generated from zygotic embryos when cultured on MS1 medium, they were subcultured on either NN basal or NN medium supplemented with IBA and within 4 - 6 weeks embryogenic callus was formed (Figure 3(a)), which differentiated into many globular to cotyledonary stage secondary embryos. The globular stage somatic embryos reached the cotyledonary stage in 4 weeks (Figure 3(b)). The cotyledons (closed) of most of the somatic embryos became opaque and milky-white to yellowish in colour (Figure $3(\mathrm{c})$ ) to light-green or green after transfer to light. Exogenous abscisic acid (ABA) treatment prevented precocious germination of immature somatic embryos in several species [28] [29]. The visible shoots emerged in the co-cultivated explants after 2 - 3 weeks in shooting culture medium. The growth of shoots derived from leaf explants was slow and the shoots rooted in rooting medium after more than 3 - 4 weeks of culture. However, the plantlets grew well when transferred to pots for 20 - 30 days (Figure 4).

Table 1. Effect of antioxidants separately as well as combined on polyphenol oxidase activity after 2 - 4, 4 - 6 and 6 - 8 weeks.

\begin{tabular}{|c|c|c|c|c|c|}
\hline \multirow{2}{*}{ S.N } & \multirow{2}{*}{ Antioxidant } & \multirow{2}{*}{$\begin{array}{c}\text { Conc. of } \\
\text { antioxidant }\end{array}$} & \multicolumn{3}{|c|}{ PPO activity } \\
\hline & & & After 2 - 4 weeks & After 4 - 6 weeks & After 6 - 8 weeks \\
\hline 01 & Ascorbic acid & $160 \mathrm{mg} / \mathrm{l}$ & $60 \%-65 \%$ & $50 \%-55 \%$ & $25 \%-30 \%$ \\
\hline 02 & Ascorbic acid & $320 \mathrm{mg} / \mathrm{l}$ & $50 \%-60 \%$ & $45 \%-50 \%$ & $20 \%-25 \%$ \\
\hline 03 & Ascorbic acid & $640 \mathrm{mg} / \mathrm{l}$ & $45 \%-50 \%$ & $35 \%-40 \%$ & $15 \%-20 \%$ \\
\hline 04 & Citric acid & $160 \mathrm{mg} / \mathrm{l}$ & $50 \%-55 \%$ & $25 \%-30 \%$ & $15 \%-20 \%$ \\
\hline 05 & Citric acid & $320 \mathrm{mg} / \mathrm{l}$ & $45 \%-50 \%$ & $20 \%-25 \%$ & $15 \%-20 \%$ \\
\hline 06 & Citric acid & $640 \mathrm{mg} / \mathrm{l}$ & $25 \%-30 \%$ & $15 \%-20 \%$ & $10 \%-15 \%$ \\
\hline 07 & Citric acid \& Ascorbic acid & $(160+160) \mathrm{mg} / \mathrm{l}$ & $30 \%-35 \%$ & $10 \%-15 \%$ & NO \\
\hline 08 & Citric acid \& Ascorbic acid & $(320+320) \mathrm{mg} / \mathrm{l}$ & $25 \%-30 \%$ & $10 \%-15 \%$ & NO \\
\hline 09 & Citric acid \& Ascorbic acid & $(640+640) \mathrm{mg} / \mathrm{l}$ & $10 \%-15 \%$ & $5 \%-10 \%$ & NO \\
\hline
\end{tabular}




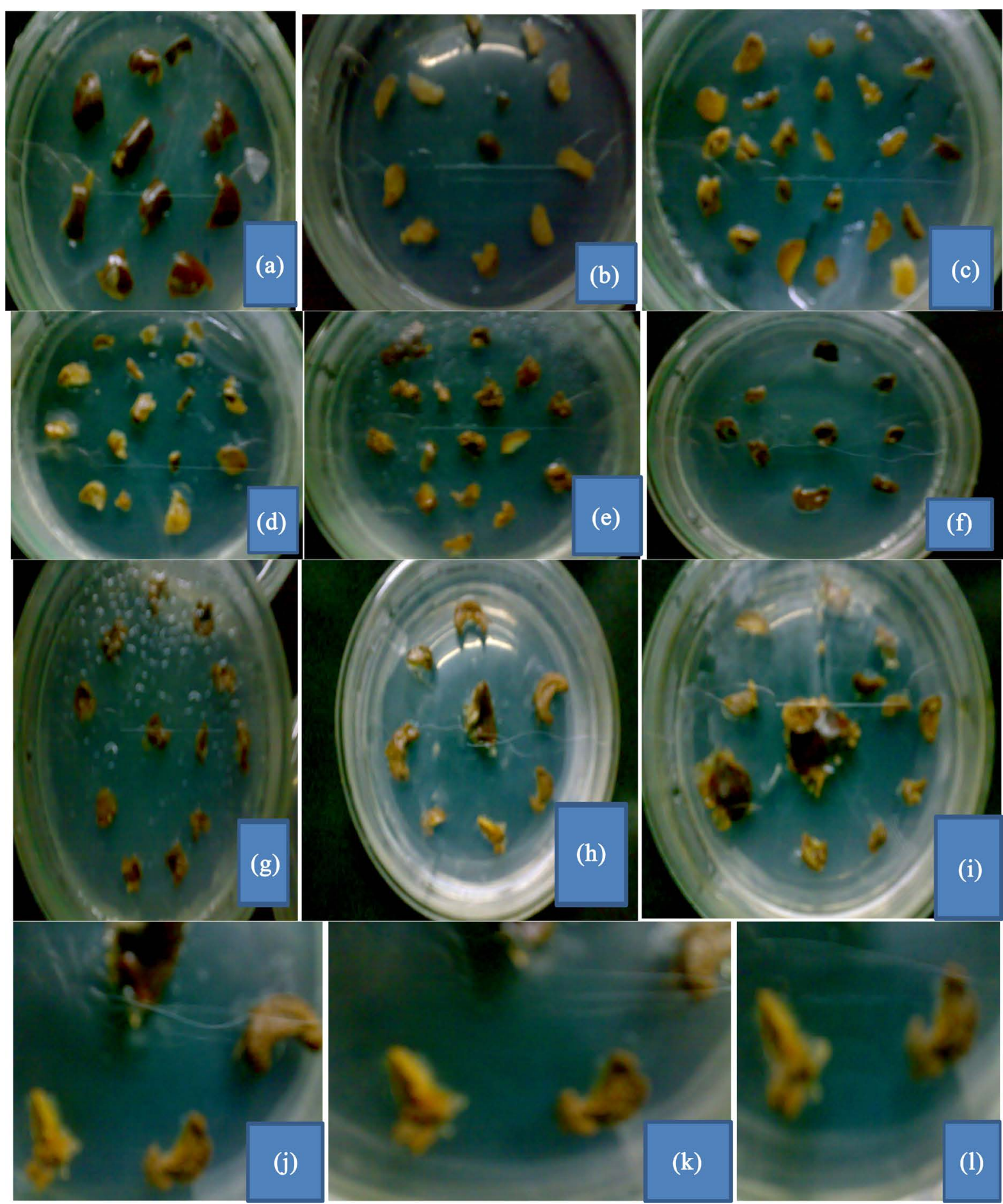

Figure 2. (a) Showing browning without antioxidant treatment, (b) Treatment with AA, (c) Treatment with CA, (d) Treatment with AA and CA, (e) Calli response in AA treatment in MS1 media, (f) Calli response in CA treatment in MS1 media, (g) Calli response after 3 - 4 weeks with CA and AA treatment in MS1 media, (h) Calli response after 6 - 7 weeks with CA and AA treatment in MS1 media, (i) Calli response after 8 - 9 weeks with CA and AA treatment in MS1 media, (j), (k) \& (l) Showing proliferation of calli after 10 - 11 weeks interval in MS2 media.

\subsection{Transgene Integration and Expression}

The presence of SAMDC in putative transgenic plants was confirmed by PCR analysis. The expected amplified 
product of $1.9 \mathrm{~kb}$, specific to SAMDC gene was obtained (Figure 5). The PCR positive plants were analyzed by Southern hybridization to identify the integration and copy number of the transgene. The transgenics showed one or two copy insertions of the transgene in tested plants (Figure 6). The transgenic lines showed high trans-
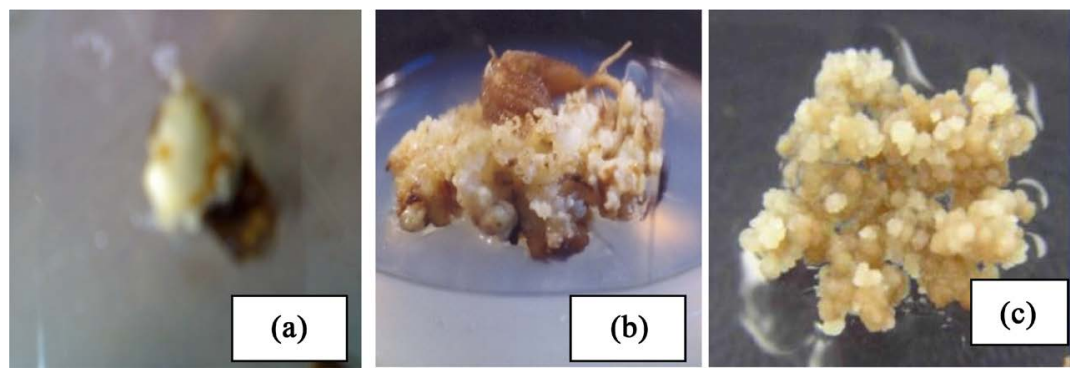

Figure 3. (a) Embryogenic calli originated from zygotic embryos of cultivar Bedana; (b) Globular somatic embryos differentiated from embryogenic calli; (c) Cotyledonary stage somatic embryos.
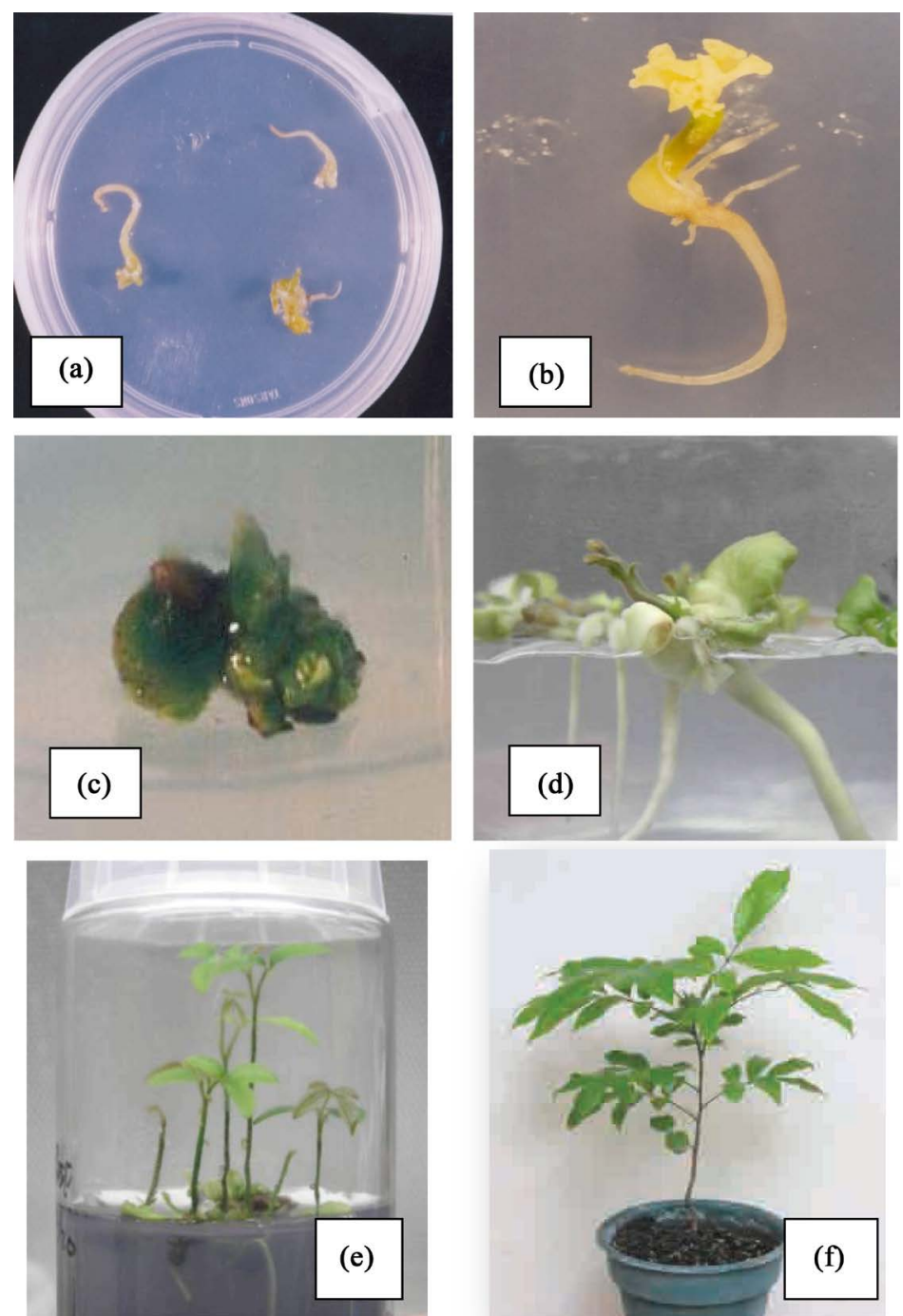

Figure 4. (a) Emergence of shoot meristem at the tip of elongated somatic embryo; (b) In somatic embryos roots are elongated in liquid medium; ((c)-(d)) Development of sturdy root and shoot systems in semi-solid medium; (e) In vitro grown litchi plantlets in semi solid medium; (f) Acclimatized in vitro litchi plantlets were transferred into field soil. 


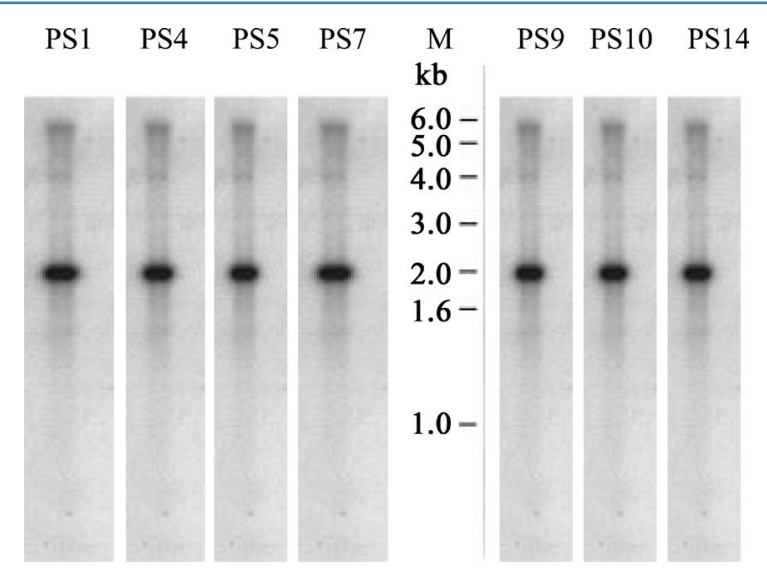

Figure 5. This figure shows PCR analysis of SAMDC gene sequence. Agarose gel electrophoresis of PCR amplification was performed with primers for the SAMDC gene sequence (Lane 1, 2, 3, 4, 6, 7 \& 8); molecular size marker (Lane 5): PCR product clones showing the expected $1.9 \mathrm{~kb}$.

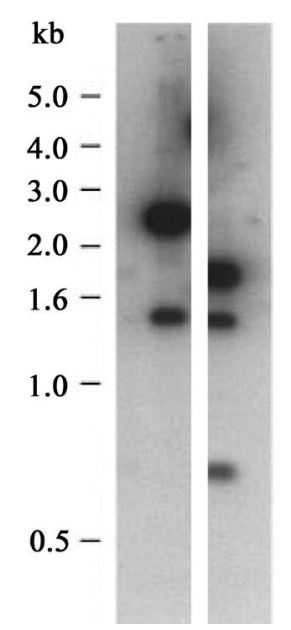

Figure 6. Analysis of the isolated SAMDC gene structure by Southern-blot analysis. The SAMDC-lambda phage DNA was digested with Sac I (lane 1), Sac I/EcoRV (lane 2), size-fractionated on a 0.8\%-agarose gel, transferred on to a nylon membrane and hybridized with a [32P]dATP-labelled datura SAMDC cDNA. The corresponding sizes (in kb) of the hybridizing fragments are indicated on the left.

gene expression at the transcript level by RT-PCR using SAMDC gene-specific primers, while not in wild type plants (Figure 7). The inserted SAMDC was further confirmed by Northern blot analysis, transgenic plants showed high transgene expression at the transcript level (Figure 8). The expression levels were, however, variable among the transgenic lines.

\subsection{Polyamine Metabolism}

The transgenic lines showed significant increase in Spd and Spm levels when compared with wild-type plants and pBI121 plants. In wild-type plants, the Spd and Spm contents were $25.2 \%$ and $38 \%$ respectively in normal condition. However, in the transgenic lines, Spd contents were increased by $94 \%$ - 135\% while Spm contents increased by $51.7 \%$ - 93.9\% and, when compared with wild-type plants. The levels of accumulated polyamines were much higher in all transgenic litchi plants than in wild-type ones. On average, Spd and Spm in transgenic lines were increased by $114 \%$ and $69.7 \%$ respectively under normal condition compared with wild-type plants. Different transgenic lines showed variations in the increased levels of PAs. Transgenic lines showed significantly different in putrescin (Put) level grown under control condition. Put content increased from 14.4\% - 30.3\% compared with the wild-type plants (Table 2). On the contrary, Put level in the non-transformed plants and pBI121 plants remained unchanged. 


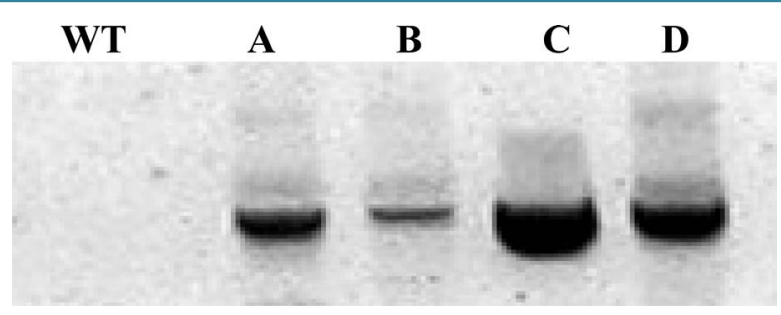

Figure 7. RT-PCR analysis for transgene expression at transcript level using primers specific to Datura SAMdc gene. The RNA from wild-type plant and different transgenic plants ((A), (B), (C) \& (D)).

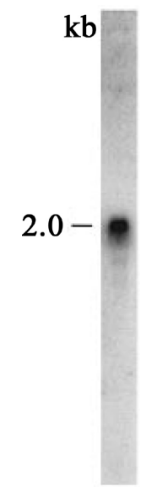

Figure 8. Northern-blot analysis of DNA from Transgenic plant. Total DNA (30 $\mu \mathrm{g})$ from transgenic plant was on a $0.8 \%$-agarose gel, transferred on to a nylon membrane and hybridized with a [32P]dATP-labelled transgenic plant SAMDC cDNA. The expected sizes $(1.9 \mathrm{~kb})$ of the hybridizing fragments are indicated on the left.

Table 2. Polyamine level in leaves from in 5 vivo-grown litchi plants of non-transgenic plants and transgenic lines B2 and Q5 with or without high temperature treatment.

\begin{tabular}{cccc}
\hline Plants & Spermidine & Spermine & Putrescine \\
Non-transgenic & $165 \pm 25$ & $51 \pm 7.8$ & $193 \pm 34$ \\
Transgenic A & $379 \pm 52$ & $85 \pm 19$ & $225 \pm 30$ \\
Transgenic B & $424 \pm 65$ & $91 \pm 14$ & $253 \pm 41$ \\
\hline
\end{tabular}

Values (nmol/g fresh weight) represent average of data from three independent experiments and are shown as means \pm S.E. Different letters in column indicate significant differences $(P<0.05)$ between means of different transgenic lines and wild-type with Duncan's multiple range test.

\section{Discussion}

It is known that the shelf life of harvested fruit is associated with maintenance of high concentrations of polyamines. Increased levels of Spd and Spm under stress condition have been implicated in radical scavenging mechanisms [30] [31] reported that transgenic eggplants with oat ADC gene exhibited increased polyamine content and an enhanced tolerance level to multiple abiotic stresses. In the present study, transformation with dSAMDC in litchi plant significantly increased PAs accumulation, especially Spm and Spd under high temperature condition. Spd and Spm increased 2.4-fold and 1.7-fold respectively on average in transgenic 1 lines compared with wild-type plants (Table 2). Increased Spd and Spm levels are usually associated with enhanced plant tolerance to unfavourable conditions [32]. Spm accumulation is associated with the stabilization of the membranes and cell constituents through binding with negatively charged groups [33]. On the other hand, we found that increase in Put was no significant difference between transgenic plants and wild-type plants. These results suggested that plants over-expressing $S A M D C$ genes with high endogenous PA levels would be very important for abiotic stress tolerance that may be implemented by PA involvement of signal transduction pathways associated with this process [34]-[37]. The genetic engineering of the synthesis of polyamine to tolerate abiotic stress for shelf life improvement of litchi appears promising [36] [37].

Another possible explanation is that the apparent increase protection of photosynthesis from SAMDC could therefore result from an effect on carotene accumulation, which directly affected the xanthophylls cycles. Enhanced carotene content in SAMDC transgenic plants provides the clues that polyamine could apparently affect 
carotene biosynthesis [21].

As antioxidants, polyamines may protect against oxidative degradation and membrane damage, resulting in maintenance of homeostasis in plant cells [38]. Enhancing the PA accumulation was found to be associated with increased antioxidant enzyme activities under stress condition. [39] proved that over expression of SAMDC in tobacco could induce high mRNA levels of several antioxidant enzymes, such as ascorbate peroxidase, superoxide dismutase and glutathione $S$-transferase in transgenic plants. PAs were shown to function mainly as a scavenger of free superoxide radicals under conditions of weak stress, whereas under conditions of strong stress they mainly acted as positive modulators of antioxidant genes [40] [41]. In the present study, an increase in Spd, Spm and total free polyamine level were found under in vitro condition, which accompanied with the markedly increased fruit flavour, color quality including fruit ripening time in transgenic Litchi plants (tropical plant). These results suggested that possible mechanism of shelf life improvement of fruit was due to increase in polyamines with marked increase of antioxidant enzyme activities and alleviate the membrane damage caused by reactive oxygen species (ROS) during abiotic stress. [41]-[46] have demonstrated that Spd and Sam (levels in tomato leaves could have a protective role against heat stress-induced ROS. In summary, in the present paper, a $d S A M D C$ cDNA from datura was expressed in litchi, the transgenic progeny, belonging to two different lines, were compared with wild type and the empty vector-transformed (pBI121) control in 1 terms of PA metabolism play a vital role in shelf life improvement of fruit quality in response to abiotic stress. The introduction of dSAMDC gene into litchi increased the PAs accumulation and antioxidant enzyme activity which increase the shelf life of fruit by delaying the ripening of fruit in tropical nonclimatric trees plant.

\section{Conclusion}

This is a very important work in which nonclimatric fruit's shelf-life is enhanced with the help of SAMDC gene which produces polyamines (spermine and spermidine) and consequently synthesises more lycopenes, product of more phytonutrients and enhances fruit juice quality. It enhances flavour, red tinge of litchi fruit which attracts consumers and high polyamine concentration has enhanced the shelf-life of fruit so that it can be exported to different parts of the world and enhances the economy of both growers and the country. The ripening of nonclimatric fruit is not dependant on respiration. The S-adenosylmethionine decarboxylase acts on SAM (Sadenosyl metionine) and converts it into polyamines so that very small amount of SAM is available to produce ethylene and consequently ripening process can be delayed and consequently fruit's shelf life can be enhanced.

\section{Acknowledgements}

Authors are grateful to University Grant Commission, New Delhi for providing financial assistance to do this work. Mr. Manoj Prabhakar, Senior Research Fellow is also highly grateful to UGC New Delhi for Fellowship.

\section{Integrity of Research and Reporting}

All authors Prabhakar M. (Senior Research fellow), Dipti Kumari, Nutan Kumari and Das D. K. (Corresponding author) belong to same institution and area and there is no conflict of interest in research coordination. We are reporting that our research is original and useful in in-vitro research in another plant species also.

\section{References}

[1] Menzel, C.M. and Simpson, D.R. (1987) Lychee Nutrition: A Review. Scientific Horticulture, 31, $195-224$. http://dx.doi.org/10.1016/0304-4238(87)90046-X

[2] Tongdee, S.C. (1994) Sulphur Dioxide Fumigation in Post Harvest Handling of Fresh Longan and Litchi for Export. In: Champ, B.R., Highley, E. and Johnson, G.I. Eds., Postharvest Handling of Tropical Fruits, Australia Centre for International Agricultural Research, Canberra, 186-195.

[3] Ray, P.K. (1998) Post-Harvest Handling of Litchi Fruits in Relation to Colour Retention-A Critical Appraisal. Journal of Food Science and Technology, 35,103-116.

[4] Chen, Y.Z. and Wang, Y.R. (1989) Study on Peroxidases in Litchi Pericarp. Acta Batanica Austro Sinica, 5, 47-52.

[5] Nip, W.K. (1988) Handling and Preservation of Lychee (Litchi chinensis Sonn.) with Emphasis on Color Relation. Tropical Science, 28, 5-11. 
[6] Huang, S., Hart, H., Lee, H. and Wicker, L. (1990) Enzymatic and Color Changes during Post-Harvest Storage of Lychee Fruit. Journal of Food Science, 55, 1762-1763. http://dx.doi.org/10.1111/j.1365-2621.1990.tb03623.x

[7] Kaur-Sawhney, R., Shih Flores, H.E. and Galston, A.W. (1982) Relation of Polyamine Synthesis and Titer to Aging and Senescence in Oat Leaves. Plant Physiology, 69, 405-410. http://dx.doi.org/10.1104/pp.69.2.405

[8] Muhitch, M.J., Edwards, L.A. and Fletcher, J.S. (1983) Influence of Diamines and Polyamines on the Senescence of Plant Suspension Cultures. Plant Cell Reports, 2, 82-84. http://dx.doi.org/10.1007/BF00270171

[9] Kakkar, R.J. and Rai, V.K. (1993) Plant Polyamines in Flowering and Fruit Ripening. Phytochemistry, 33, $1281-1288$. http://dx.doi.org/10.1016/0031-9422(93)85076-4

[10] Apelbaum, A., Burgoon, A.C., Anderson, J.D., Lieberman, M., Ben-Arie, R. and Mattoo, A.K. (1981) Polyamines Inhibits Synthesis of Ethylene in Higher Plants. Plant physiology, 68, 453-456. http://dx.doi.org/10.1104/pp.68.2.453

[11] Suttle, J.C. (1981) Effect of Polyamines on Ethylene Production. Phytochemistry, 20, 1477-1480. http://dx.doi.org/10.1016/S0031-9422(00)98515-7

[12] Even-Chen, Z., Mattoo, A.K. and Goren, R (1982) Inhibition of Ethylene Biosynthesis by Aminoethoxyvinylglycine and by Polyamines Shunt Label from C14-Methionine into Spermidine in Aged Orange Peel Discs. Plant Physiology, 69, 385-388. http://dx.doi.org/10.1104/pp.69.2.385

[13] Fuhrer, J., Kaur-Sawhney, R., Shih, L.M. and Galston, A.W. (1982) Effects of Exogenous 1, 3-Diaminopropane and Spermidine on Senescence of Oat Leaves. II. Effects of Polyamines on Ethylene Biosynthesis. Plant Physiology, 70, 1597-1600. http://dx.doi.org/10.1104/pp.70.6.1597

[14] Apelbaum, A., Goldlust, A. and Icekson, I. (1985) Control by Ethylene of Arginine Decarboxylase Activity in Pea Seedlings and Its Implication for Hormonal Regulation of Plant Growth. Plant Physiology, 79, 635-640. http://dx.doi.org/10.1104/pp.79.3.635

[15] Icekson, I., Goldlust, A. and Apelbaum, A. (1985) Influence of Ethylene on S-Adenosylmethionine Activity in Etiolated Pea Seedlings. Journal of Plant Physiology, 119, 335-345. http://dx.doi.org/10.1016/S0176-1617(85)80101-2

[16] Montague, M.J., Koppenbrink, J.W. and Jaworski, E.G. (1978) Polyamine Metabolism in Embryogenic Cells of Daucus carota. Plant Physiology, 62, 430-433. http://dx.doi.org/10.1104/pp.62.3.430

[17] Feirer, R.P., Mignon, G. and Litvay, J.D. (1984) Arginine Decarboxylase and Polyamines Required for Embryogenesis in Wild Carrot. Science, 223, 1433-1434. http://dx.doi.org/10.1126/science.223.4643.1433

[18] Heimer, Y.M. and Mizrahi, Y. (1982) Characterization of Ornithine Decarboxylase of Tobacco Cells and Tomato Ovaries. Biochemical Journal, 201, 373-376. http://dx.doi.org/10.1042/bj2010373

[19] Slocum, R.D. and Galston, A.W. (1985) Changes in Polyamine Biosynthesis Associated with Post-Fertilization Growth and Development in Tobacco Ovary Tissue. Plant Physiology, 79, 336-343. http://dx.doi.org/10.1104/pp.79.2.336

[20] Torrigiani, P., Scaramagli, S., Ziosi, V., Mayer, M. and Biondi, S. (2005) Expression of an Antisense Datura stramonium S-Adenosylmethionine Decarboxylase cDNA in Tobacco: Changes in Enzyme Activity, Putrescine-Spermidine ratio, Rhizogenic Potential, and Response to Methyl Jasmonate. Journal of Plant Physiology, 162, 559-571. http://dx.doi.org/10.1016/j.jplph.2004.10.008

[21] Mehta, R.A., Cassol, T., Li., N., Ali, N., Handa, A.K. and Mattoo, A.K. (2002) Engineered Polyamine Accumulation in Tomato Enhances Phytonutrient Content, Juice Quality, and Vine Life. Nature Biotechnology, 20, 613-618. http://dx.doi.org/10.1038/nbt0602-613

[22] Ding, S.L., Li, J.Y., Zhou, Y.J., Lu, G. and Cao, J.S. (2006) Construction of the Gene Expression Vector of Yeast SAMDC and Tomato Transformation Mediated by Agrobacterium tumefaciens. Journal of Zhejiang University (Agriculture \& Life Sciences), 32, 621-627.

[23] Yu, C. and Chen, Z.G. (1997) Induction of Litchi Embryogenic Calli by Immature Embryos and Anthers Culture in Vitro. Journal of Fujian Agricultural University, 26, 168-172.

[24] Yu, C., Chen, Z., Lu, L. and Lin, J. (2000) Somatic Embryogenesis and Plant Regeneration from Litchi Protoplasts Isolated from Embryogenic Suspensions. Department of Horticulture, Fujian Agricultural University, Plant Cell, Tissue and Organ Culture, 61, 51-58. http://dx.doi.org/10.1023/A:1006446506041

[25] Merkle, S.A., Parrott, W.A. and Flinn, B.S. (1995) Morphogenic Aspects of Somatic Embryogenesis. In: Thorpe, T.A., Ed., In Vitro Embryogenesis in Plants, Kluwer Academic Publishers, Dondrecht, 155-203. http://dx.doi.org/10.1007/978-94-011-0485-2_5

[26] Sambrook, J., Fritsch, E.F. and Maniatis, T. (1989) Molecular Cloning: A Laboratory Manual. 2nd Edition, Cold Spring Harbor Laboratory Press, New York.

[27] Minocha, S.C., Minocha, R. and Robif, C.A. (1990) High-Performance Liquid Chromatographic Method for the Determination of Dansyl Polyamines. Journal of Chromatography, 511,177-183. http://dx.doi.org/10.1016/S0021-9673(01)93283-2 
[28] Bapat, V.A. and Rao, P.S. (1992) Plantlet Regeneration from Encapsulated and Non-Encapsulated Dessicated Somatic Embryos of a Forest Tree: Sandalwood (Santalum album L.). Plant Biochem Biotechnoogy, 1, 109-113. http://dx.doi.org/10.1007/BF03262907

[29] Attree, S.M., Pomeroy, M.K. and Fowke, L.C. (1994) Production of Vigorous, Desiccation Tolerant White Spruce (Picea glauca Moench Voss) Synthetic Seeds in a Bioreactor. Plant Cell Reports, 13, 601-606. http://dx.doi.org/10.1007/BF00232929

[30] Lester, G.E. (2000) Polyamines and Their Cellular Antisenescence Properties in Honey Dew Muskmelon Fruit. Plant Science, 160, 105-112. http://dx.doi.org/10.1016/S0168-9452(00)00369-1

[31] Prabhavathi, V.R. and Rajam, M.V. (2007) Polyamine Accumulation in Transgenic Eggplant Enhances Tolerance to Multiple Abiotic Stresses and Fungal Resistance. Plant Biotechnology, 24, 273-282. http://dx.doi.org/10.5511/plantbiotechnology.24.273

[32] Jiménez-Bremont, J.F., Oscar, A., Ruiz, O.A. and Rodríguez-Kessler, M. (2007) Modulation of Spermidine and Spermine Levels in Maize Seedlings Subjected to Long-Term Salt Stress. Plant Physiology and Biochemistry, 45, 812-821. http://dx.doi.org/10.1016/j.plaphy.2007.08.001

[33] Ha, H.C., Sirisoma, N.S., Kuppusamy, P., Zweiler, J.L., Woster, P.M. and Casero Jr., R.A. (1998) The Natural Polyamine Spermine Functions Directly as a Free Scavenger. Proceedings of the National Academy of Sciences of the United States of America, 95, 11140-11145. http://dx.doi.org/10.1073/pnas.95.19.11140

[34] Sairam, R.K. and Tyagi, A. (2005) Physiology and Molecular Biology of Salinity Stress Tolerance in Plants. Current Science, 86, 407-421.

[35] Kasukabe, Y., He, L., Nada, K., Misawa, S., Ihara, I. and Tachibana, S. (2004) Overexpression of Spermidine Synthase Enhances Tolerance to Multiple Environmental Stress and Up-Regulates the Expression of Various Stress-Regulated Genes in Transgenic Arabidopsis thaliana. Plant Cell Physiology, 45, 712-722. http://dx.doi.org/10.1093/pcp/pch083

[36] Vinocur, B. and Altman, A. (2005) Recent Advances in Engineering Plant Tolerance to Abiotic Stress: Achievements and Limitations. Current Opinion in Biotechnology, 16, 123-132. http://dx.doi.org/10.1016/j.copbio.2005.02.001

[37] Alcázar, R., Marco, F., Cuevas, J.C., Patron, M., Ferrando, A. and Carrasco, P. (2006) Involvement of Polyamines in Plant Response to Abiotic Stress. Biotechnology Letters, 28, 1867-1876. http://dx.doi.org/10.1007/s10529-006-9179-3

[38] Rodrị́guez-Kessler, M., Alpuche-Solís, A.G., Ruiz, O.A. and Jiménez-Bremont, J.F. (2006) Effect of Salt Stress on the Regulation of Maize (Zea mays L.) Genes Involved in Polyamine Biosynthesis. Plant Growth Regulators, 48, 175-185. http://dx.doi.org/10.1007/s10725-005-5990-4

[39] Wi, S.J., Kim, W.T. and Park, K.Y. (2006) Overexpression of Carnation S-Adenosylmethionine Decarboxylase Gene Generates a Broad-Spectrum Tolerance to Abiotic Stresses in Transgenic Tobacco Plants. Plant Cell Reports, 25, 1111-1121. http://dx.doi.org/10.1007/s00299-006-0160-3

[40] Tkachenko, A.G. and Nesterova, L.Y. (2004) Polyamines as Modulators of Gene Expression under Oxidative Stress in Escherichia Coli. Biochemistry, 68, 850-856.

[41] Liu, J.H., Kitashiba, H., Wang, J., Ban, Y. and Moriguchi, T. (2007) Polyamines and Their Ability to Provide Environmental Stress Tolerance to Plants. Plant Biotechnology, 24, 117-126. http://dx.doi.org/10.5511/plantbiotechnology.24.117

[42] Seymour G.B., Osterguard, L. and Chagman. N.H. (2013) Fruit Development and Ripening. Annual Review of Plant Biology, 64, 219-241. http://dx.doi.org/10.1146/annurev-arplant-050312-120057

[43] Pathak, R.M., Desilva, J.A.T. and Want, S.H. (2014) Polyamines in Response to Abiotic Stress Tolerance through Transgenic Approaches. G M Crops Food, 5, 87-96.

[44] Harindra Champa, W.A., Gilla, M.I.S., Mahajanb, B.V.C. and Bedic, S. (2015) Exogenous Treatment of Spermine to Maintain Quality and Extend Post Harvest Life of Table Grapes (Vitis vinifera L) cv. Flame Seedless. LWT Food Science and Technology, 60, 412-419. http://dx.doi.org/10.1016/j.lwt.2014.08.044

[45] Sathe, A.P., Paserkar, N.G., Thakare M.B. and Gaikward S.M. (2015) Engineering Polyamines for Abiotic Stress Tolerance. Biotechnology, 5, 1-5.

[46] Mo, H., Wang, X., Zhang, Y., Zhang, G., Zhang, J.F. and Ma, Z.Y. (2015) Cotton Polyamine Oxidase Is Required for Spermine and Camalexin Signalling in the Defence Response to Verticillium datiae. The Plant Journal, 83, 962-975. http://dx.doi.org/10.1111/tpj.12941 